\title{
Technique and results after immediate orthotopic replantation of extracorporeally irradiated tumor bone autografts with and without fibular augmentation in extremity tumors
}

Alexander Klein ${ }^{1 *}$ (D), Yasmin Bakhshai ${ }^{2}$, Falk Roeder ${ }^{3}$, Christof Birkenmaier $^{2}$, Andrea Baur-Melnyk ${ }^{4}$ and Hans Roland Dürr'

\begin{abstract}
Background: Reconstruction of the skeletal defects resulting from the resection of bone tumors remains a considerable challenge and one of the possibilities is the orthotopic replantation of the irradiated bone autograft. One technical option with this technique is the addition of a vital autologous fibular graft, with or without microvascular anastomosis. The aim of our study was to evaluate the clinical results of the treatment of our patient cohort with a specific view to the role of fibular augmentation.

Methods: Twenty-one patients with 22 reconstructions were included. In all cases, the bone tumor was resected with wide margins and in 21 of them irradiated with $300 \mathrm{~Gy}$. In the first case, thermal sterilization in an autoclave was used. The autograft was orthotopically replanted and stabilized with plates and screws. Fifteen patients underwent an additional fibular augmentation, 8 of which received microvascular anastomoses or, alternatively, a locally pedicled fibular interposition.

Results: the most common diagnosis was a Ewing sarcoma (8 cases) and the most common location was the femur (12 cases). The mean follow-up time was 70 months (16-154 months). For our statistical analysis, the one case with autoclave sterilization and 3 patients with tumors in small bones were excluded. During follow-up of 18 cases, $55.6 \%$ of patients underwent an average of 1.56 revision surgeries. Complete bony integration of the irradiated autografts was achieved in $88.9 \%$ of cases after 13.6 months on average. In those cases with successful reintegration, the autograft was shorter (n.s.). Microvascular anastomosis in vascularized fibular strut grafts did not significantly influence the rate of pseudarthrosis.
\end{abstract}

\footnotetext{
* Correspondence: alexander.klein@med.uni-muenchen.de

'Musculoskeletal Oncology, Department of Orthopaedics, Physical Medicine and Rehabilitation, University Hospital, Marchioninistr. 15, 81377 Munich, Germany

Full list of author information is available at the end of the article
}

(c) The Author(s). 2021, corrected publication 2021. Open Access This article is licensed under a Creative Commons Attribution 4.0 International License, which permits use, sharing, adaptation, distribution and reproduction in any medium or format, as long as you give appropriate credit to the original author(s) and the source, provide a link to the Creative Commons licence, and indicate if changes were made. The images or other third party material in this article are included in the article's Creative Commons licence, unless indicated otherwise in a credit line to the material. If material is not included in the article's Creative Commons licence and your intended use is not permitted by statutory regulation or exceeds the permitted use, you will need to obtain permission directly from the copyright holder. To view a copy of this licence, visit http://creativecommons.org/ licenses/by/4.0/. The Creative Commons Public Domain Dedication waiver (http://creativecommons.org/publicdomain/zero/1. 0/) applies to the data made available in this article, unless otherwise stated in a credit line to the data. 
Conclusions: the replantation of extracorporeally irradiated bone autografts is an established method for the reconstruction of bone defects after tumor resection. Our rate of complications is comparable to those of other studies and with other methods of bone reconstruction (e.g. prosthesis). In our opinion, this method is especially well suited for younger patients with extraarticular bone tumors that allow for joint preservation. However, these patients should be ready to accept longer treatment periods.

Keywords: Irradiated bone, Bone reconstruction, Bone tumor, Fibular graft, Pseudarthrosis, Autograft

\section{Background}

Most primary malignant bone tumors are localized in the long bones with the majority occurring in the meta -/epiphyses whereas about $10 \%$ affect the diaphyseal part of the long bones [1]. The resection of these tumors causes large defects in these load-bearing bones and their reconstruction represents a challenge. Biological as well as endoprosthetic methods for the reconstruction of long bone continuity have been developed. Biological reconstruction methods include the use of allografts, segmental transport or the reimplantation of sterilized resected bone segments [2] with each of these methods entailing specific advantages and disadvantages. The long-term problems are infection, graft necrosis, implant loosening or pseudarthrosis. The reimplantation of a sterilized autograft offers the advantages of a perfect anatomical match and immediate availability. The available methods for the devitalization of the bone autograft are sterilization by irradiation, deep-freezing using fluid nitrogen and pasteurization [2]. Our center has a longstanding experience with the sterilization of tumorbearing bone autografts by irradiation. This technique was first described by Spira et al. in 1968 [3] and has since become established in the treatment of malignant bone tumors. It allows for an anatomic reconstruction and later bone remodeling especially in young patients [4]. However, there are only few reports with series including more than 15 patients.

There are two major problems with this strategy: One is the creeping resorption of the autograft, the other is the reported high rate of pseudarthroses. In order to combat these issues, the augmentation of the irradiated autograft with a vascularized or a non-vascularized fibula segment is an option. Until now, the role of fibular augmentation of an irradiated autograft has not been fully established.

\section{Methods}

The aim of our study was to evaluate the outcomes of the treatment of malignant bone tumors by replantation of the extracorporeally irradiated bone segments, to establish the rate of successful bone healing and to evaluate the role of fibular augmentation (vascularized or non-) of the reconstruction. Additional factors, which might influence the result, were also analyzed.
This retrospective analysis was performed based on our tumor database and current follow-up data. We identified 21 consecutive patients with 22 resections, irradiation and replantation of the tumor bone segment, operated between 1999 and 2015. The same surgeon treated all patients. The indications for this procedure were the following:

- Bone defect after wide resection of a tumor

- Localization of the tumor in the long bone

- Sufficient structural stability of the segment to be resected and replanted

The diagnosis of the tumor was ascertained by an incisional or a core-needle biopsy based on radiological imaging (magnetic resonance imaging (MRI), computed tomography (CT)- and/or positron emission tomographycomputed tomography (PET-CT) scan). Primary bone tumors as well as metastases of other tumor entities were included. Systemic therapy was applied in some patients depending on the requirements of the underlying tumor condition. The indication for wide resection was either a primary bone tumor or metastatic disease in selected cases of cancers less sensitive to radiation (e.g. renal cell carcinoma) as a curative approach.

There were 9 female and 12 male patients. The range of the age at the time of operative treatment was between 10 and 83 years (median age 36.4 years), 3 of them younger than 18 years. These 21 patients underwent 22 primary operations. One patient had a simultaneous partial femur and tibia resection. No patient was lost to follow-up.

Systemic therapy was indicated in respect to the entity of the tumor. The patient with chondrosarcoma did not receive any systemic therapy. Patients with Ewing and osteosarcomas underwent standardized chemotherapy in neoadjuvant and adjuvant settings: Euro-EWING regime for Ewing sarcomas [5]; EURO-B.O.S.S [6]. or EURAMOS [7] regime for osteosarcomas. The indication for resections of metastatic disease was a resectable lesion of the bone in selected entities as renal cell or hepatocellular carcinoma known to be less sensitive to radiotherapy. In general, patients were free of tumor after resection of the primary tumor and metastatic disease; there was no indication for systemic treatment. After wide resections of the 
tumor with clear margins, no indication for radiotherapy was seen. The only exception had been patients with Ewing sarcoma. In those cases, an adjuvant radiotherapy was discussed individually.

For sterilization we used high-dose irradiation in all but the first patient, where thermal sterilization in an autoclave was used.

In the case of fibular augmentation, harvesting the graft was the first step of surgery. The length of the fibular graft was calculated to cover both osteotomy sites. A wide resection of the tumor was subsequently performed. The explanted tumor-bearing bone segment was packed into a double sterile bag and transported to the radiation oncology department. To minimize any build-up effect and to keep radiation time short, the bag was wrapped with flab material and placed beneath the linear accelerator with the lowest possible distance to the accelerator head, usually on a tray in the accessory slot. A dose of 300 Gy (Gy) using an opposing field technique was applied in a single fraction. After radiation, the bone (fragment) was immediately returned to the operation room. During sterilization, we obtained biopsies of the bone marrow tissue from the ends of the remaining bone and from surrounding soft tissue for the evaluation of the resection margins.

In the next step, the irradiated bone was prepared for replantation, the soft tissue parts were resected as necessary (Fig. 1), followed by replantation and osteosynthesis. The fibular graft was intramedullary positioned inside the sterilized autograft (inlay technique) covering both osteotomies. In 15 patients, an augmentation with a fibular graft was used. In 8 of these 15 cases, we used a vascularized fibula or performed a pedicled fibular interposition. The decision, which method (vascularized/nonvascularized) fibula was used, depended primarily on the location. If a fibular transposition into a tibial defect was possible, we used a pedicled vascularized graft. In the first cases of femoral defects, we used free vascularized fibula grafts. Later, due to good reported experiences with non-vascularized fibula graft in literature [8], we changed our strategy and used non-vascularized grafts. The reconstruction was stabilized in long bones with one long plate osteosynthesis with anchoring proximal and distal of the osteotomy (regularly with locking screws). In most cases, the replanted graft was fixed in the plate with one monocortical screw (Fig. 2). The rehabilitation included complete non-weight bearing for 6 weeks postoperatively and gradual increase of the load of the affected extremity in dependence of the radiographic follow-up. The conventional radiographic controls were performed 6 weeks, 3, 6, 9 and 12 months after the surgery and then as required. Full weight-bearing could be achieved in general after 1012 weeks. The local tumor follow-up was done by means of MRI. The presence or absence of bony union was assessed by an experienced musculoskeletal radiologist based on the conventional radiographs obtained at follow-up (Fig. 2).
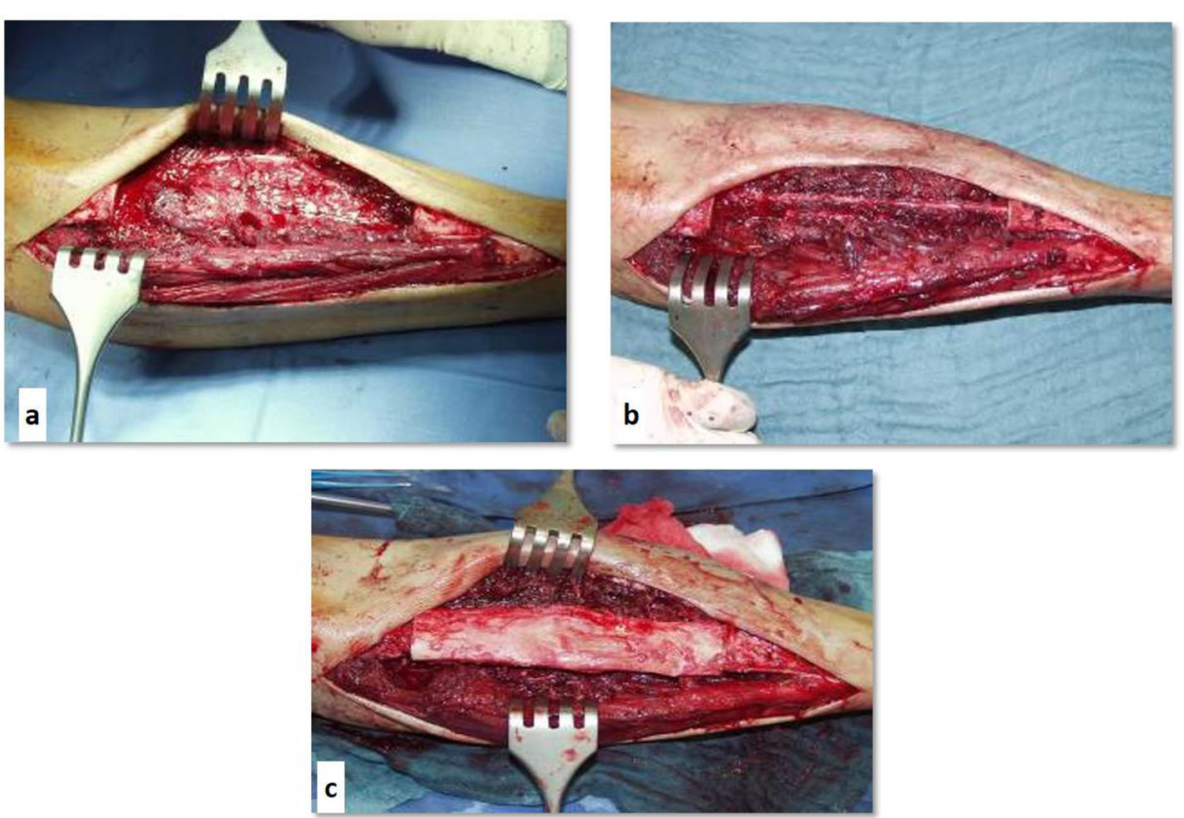

Fig. 1 Technique of tumor resection and biological reconstruction with irradiated diaphyseal tibia autograft. a: Resection of the tumor in the tibial diaphysis; $\mathbf{b}$ : Transposition of the ipsilateral fibula into the tibial defect; $\mathbf{c}$ : Interposition of the irradiated segment covering the fibular transplant prior to osteosynthesis. The plate osteosynthesis (Limited Contact Dynamic Compression Plate) was performed as next step 

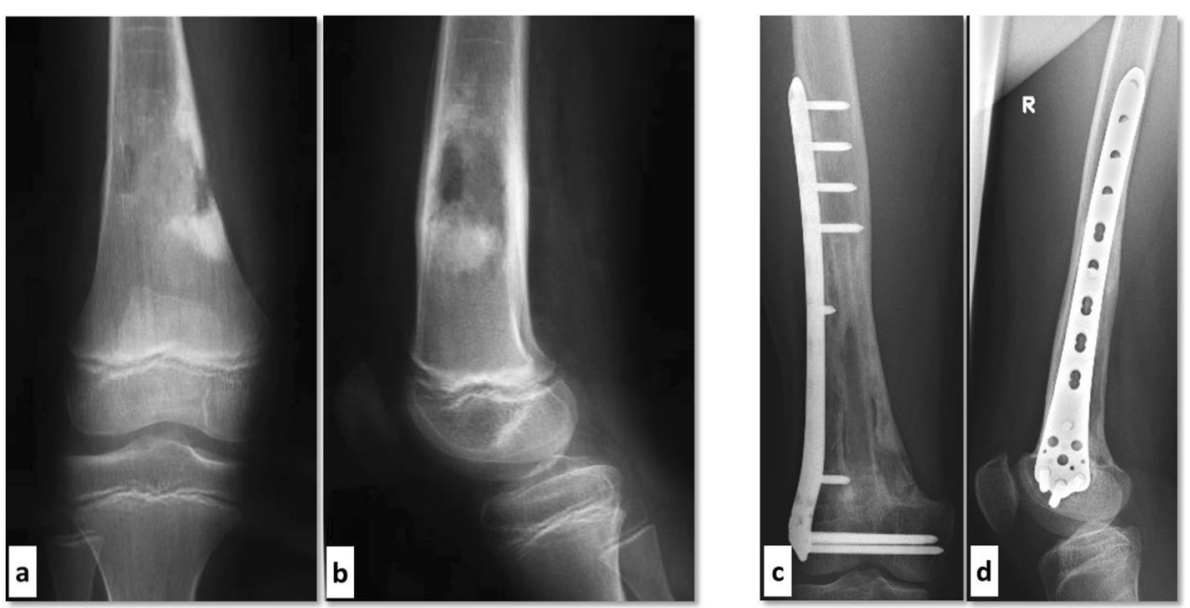

Fig. 2 Osteosarcoma of the distal femur in an 11-year-old boy; $\mathbf{a}+\mathbf{b}$ : Preoperative a.p. and lateral view; $\mathbf{c}+\mathbf{d}$ : Bony integration using a nonvascularized fibular augmentation 4 years after surgery

Significance analysis was performed using the Log-Rank test or the Chi-Square test, defining a 95\% confidence interval. The univariate analysis (Cox proportionalhazards regression) was used for the evaluation of the influence of the distance of bone resection and of the reconnection of fibular vessels on the pseudarthrosis rate. Because of the small cohort size, we re-evaluated the significance with the Fisher exact test. The level of significance was set at less than 0.05 . The data analysis software used was $\mathrm{IBM}^{\bullet} \mathrm{SPSS}^{\bullet}$ Statistics 25. The institutional ethics committee approved this study.

\section{Results}

All patients with replantation of irradiated autografts could be included. One patient underwent synchronous dual tumor resection und replantation of irradiated bone in the distal femur and in the proximal tibia for bone metastases of a renal cell carcinoma.

The diagnoses were Ewing sarcoma in 8 cases, metastatic disease in 6 cases $(5$ patients with renal cell carcinoma, one patient with hepatocellular carcinoma), osteosarcoma in 5 and one case each with high-grade chondrosarcoma, leiomyosarcoma and myxofibrosarcoma with bone involvement (Table 1). The most common site of the tumors was the femur in 12 cases, the tibia in 7 and the calcaneus in 2 cases. One patient had the tumor located in the scapula. The mean follow-up was 70 months (range between 16 and 154 months, median 58 months). In only 3 patients the follow-up was less than 2 years. In total, five patients deceased due to progressive disease during the observation period. 2.54 revisions per case were necessary in the whole cohort (range between 0 and 8).We divided the cohort in two groups of patients: 18 cases with tumor location in the long bones and 3 patients with involvement of small/flat bones ( 2 cases with calcaneus and 1 case with scapula tumor). Also the result of one case with an autoclaved autograft is described independently.

\section{Tumor control}

We observed only one locoregional recurrence in $21 \mathrm{pa}-$ tients, resulting in a local control rate of $95.5 \%$. This patient, a 13-year old boy, suffered from an osteosarcoma of the femoral diaphysis. He had been diagnosed with a pathologic fracture surrounded by a large hematoma and had initially been treated by elastic intramedullary nailing at another institution. The hip and the knee joint were not contaminated. Two surgical options after neoadjuvant chemotherapy were discussed with the patient and his parents: total femur resection and endoprosthetic reconstruction or resection of the contaminated part of femur and biological reconstruction. We subsequently performed a resection with microscopically clear margins and replantation as described in the methods section. He developed a symptomatic pseudarthrosis between the graft and the femur, which was salvaged by endoprosthetic total femur reconstruction. Nine months after endoprosthetic reconstruction, locoregional recurrence occurred (outside the initial graft area but inside the initial hematoma area), which was successfully salvaged by wide resection. We therefore attribute the locoregional recurrence to the initial fracture hematoma, which most probably had been contaminated with tumor cells. The patient is free of tumor for now 14 years.

\section{Patients with long bone tumors}

There were 11 tumors in the diaphyseal segment of the bone. Seven lesions were located in the epi-/ metaphyseal part of the bone. Out of 18 cases of replantations in long bones, 15 osteotomies were located in the metaphyseal 
Table 1 Data of patient cohort and details of surgery (sex: $m=$ male, $f=$ female; HCC: hepatocellular carcinoma; RCC: renal cell carcinoma)

\begin{tabular}{|c|c|c|c|c|c|c|c|c|c|}
\hline Pat ID & Age & Tumor Entity & Location & $\begin{array}{l}\text { Site of proximal } \\
\text { osteotomy }\end{array}$ & $\begin{array}{l}\text { Site of distal } \\
\text { osteotomy }\end{array}$ & $\begin{array}{l}\text { Fibula- } \\
\text { augmentation }\end{array}$ & $\begin{array}{l}\text { Type of } \\
\text { complication }\end{array}$ & $\begin{array}{l}\text { Number of } \\
\text { revisions }\end{array}$ & $\begin{array}{l}\text { Bony union } \\
\text { achieved }\end{array}$ \\
\hline \multicolumn{10}{|c|}{ Location in long bones } \\
\hline 1 & 10 & Ewing Sarcoma & tibia & metaphysis & diaphysis & yes/vascularized & infection & 5 & yes \\
\hline 2 & 11 & Osteosarcoma & femur & diaphysis & metaphysis & yes/vascularized & & 0 & yes \\
\hline 3 & 66 & Osteosarcoma & femur & diaphysis & metaphysis & no & pseudarthrosis & 2 & yes \\
\hline 4 & 57 & $\begin{array}{l}\text { Leiomyosar- } \\
\text { coma }\end{array}$ & tibia & metaphysis & diaphysis & yes/vascularized & & 0 & yes \\
\hline 5 & 26 & Ewing Sarcoma & femur & diaphysis & diaphysis & yes/non-vascularized & & 0 & yes \\
\hline 6 & 13 & Osteosarcoma & femur & metaphysis & metaphysis & yes/non-vascularized & pseudarthrosis & 4 & prosthesis \\
\hline 7 & 58 & HCC-Metastasis & femur & metaphysis & $\begin{array}{l}\text { epiphysis } \\
\text { including } \\
\text { cartilage }\end{array}$ & no & infection & 2 & yes \\
\hline 8 & 27 & Ewing Sarcoma & femur & metaphysis & diaphysis & yes/non-vascularized & & 0 & yes \\
\hline 9 & 37 & Osteosarcoma & femur & diaphysis & diaphysis & yes/vascularized & pseudarthrosis & 8 & yes \\
\hline 10 & 79 & RCC-Metastasis & tibia & diaphysis & $\begin{array}{l}\text { epiphysis } \\
\text { including } \\
\text { cartilage }\end{array}$ & no & hematoma & 1 & yes \\
\hline 11 & 83 & RCC-Metastasis & femur & diaphysis & metaphysis & no & pseudarthrosis & 1 & yes \\
\hline 12 & 62 & Osteosarcoma & tibia & diaphysis & diaphysis & yes/non-vascularized & & 0 & yes \\
\hline 13 & 12 & Ewing Sarcoma & femur & metaphysis & diaphysis & yes/vascularized & pseudarthrosis & 1 & pseudarthrosis \\
\hline \multirow[t]{2}{*}{14} & 73 & RCC-Metastasis & femur & diaphysis & metaphysis & yes/non-vascularized & & 0 & yes \\
\hline & & RCC-Metastasis & tibia & metaphysis & diaphysis & yes/vascularized & infection & 3 & yes \\
\hline 15 & 31 & Chondrosar-coma & tibia & $\begin{array}{l}\text { epiphysis } \\
\text { including } \\
\text { cartilage }\end{array}$ & metaphysis & no & & 0 & yes \\
\hline 16 & 68 & Myxofibrosar-coma & femur & diaphysis & metaphysis & yes/non-vascularized & pseudarthrosis & 1 & yes \\
\hline 17 & 49 & RCC-Metastasis & femur & diaphysis & metaphysis & yes/non-vascularized & & 0 & yes \\
\hline \multicolumn{10}{|c|}{ Patient with autoclaved autograft } \\
\hline 18 & 20 & Ewing Sarcoma & tibia & metaphysis & diaphysis & yes/vascularized & wound healing & 2 & yes \\
\hline \multicolumn{10}{|c|}{ Location in short/flat bones } \\
\hline 19 & 36 & Ewing Sarcoma & calcaneus & metaphysis & & no & wound healing & 2 & yes \\
\hline 20 & 32 & Ewing Sarcoma & scapula & & metaphysis & no & hematoma & 1 & pseudarthrosis \\
\hline 21 & 29 & Ewing Sarcoma & calcaneus & & & no & & 0 & $\begin{array}{l}\text { not possible } \\
\text { (total bone) }\end{array}$ \\
\hline
\end{tabular}

zone, 18 in the diaphyseal area. Three patients had a replantation of a meta-epiphyseal graft including the articular cartilage (Table 1). When comparing the time required the osteotomy to heal between diaphyseal and metaepiphyseal sector, no significant difference was observed ( $p=0.662 ; 10.8$ vs 11.4 months). Comparing the proximal and distal osteotomies, there was no significant difference in rate of pseudarthrosis $(p=0.336)$.

The length of the resected intercalary segment was not significantly correlated with the occurrence of pseudarthrosis $(p=0.229)$, but the cases with a pseudarthrosis had longer resections lengths on average $(16.9 \mathrm{~cm}$ vs $12.7 \mathrm{~cm})$.

In 13 cases, we performed a fibular augmentation Two pseudarthroses were observed after reconstruction without and 4 after reconstruction with fibular augmentation. The use of fibula strut grafts for augmentation of the autograft did not improve the pseudarthrosis rate, compared to non-augmented reconstructions $(p=$ 0.561). 7 of 13 fibular autografts were non-vascularized. There was one case of pseudarthrosis in the group of vascularized and three in the group of non-vascularized augmentations. In our statistical analysis, however, there was no significant difference between these groups ( $p=$ 0.343). With a microvascular anastomosis, the time to bony integration was 11.7 months on average (median 10.5; range 9-16 months) and 13 months in the nonvascularized group (median 10; range 8-27 months; $p=$ 0.712 , Fisher exact test $p=0.396$ ). The results of univariate analysis are shown in the Table 2. 
Table 2 Results of univariate analysis regarding the risk of pseudarthrosis in cases involving the long bones

\begin{tabular}{ll}
\hline & $\boldsymbol{p}$-value \\
\hline Location in bone (diaphyseal vs. meta-/epiphyseal) & 0.662 \\
Location in bone (proximal vs. distal osteotomy) & 0.336 \\
Length of the resection & 0.229 \\
Use of fibular graft & 0.561 \\
Vascularization of fibula graft & 0.343 \\
\hline
\end{tabular}

\section{Graft integration}

The results from 18 cases with such reconstructions were evaluated. (Table 1). Complete bony integration of the irradiated autograft was ultimately achieved in 16 of 18 lesions (88.9\%) after a mean time of 13.6 months (range 4-35, median 10 months) and - in several instances - revisions for initial non-union (see below). In total, 6 patients with long bone reconstruction developed pseudarthrosis, 4 united, one necessitated an endoprosthesis (because of local recurrence) and one remained asymptomatic and did not require any further surgical treatment. 4 of 6 pseudarthrotic osteotomies were located in metaphyseal and also four of 6 in the proximal part of the bone. From all symptomatic pseudarthroses the failure of osteosyntheses did cause the pain. We used for revision autologous spongiosa from the iliac crest and re-osteosynthesis with a plate. Between 1 and 8 revisions (on average 3 per case) were necessary in cases of pseudarthroses. Limb preservation was achieved in all patients.

\section{Complications}

We observed complications that required surgical revision in 10 out of 18 cases (55.6\%). 6 of those were caused by symptomatic pseudarthrosis with failure of the reconstruction and led to at least one surgical revision per patient. Three Patients needed an additional operation because of a surgical site infection and 1 because of wound hematoma 3 . In total, 28 revisions were necessary (average 1.56 revisions per case). There were no cases of autograft fracture (Table 1).

\section{Patients with reconstructions at the small/flat bones or after autoclaving}

Patient 1.

20-year-old patient with recurring Ewing sarcoma of the proximal tibia. She was the first patient in our cohort. In this case only we used thermal sterilization in an autoclave. We used the ipsilateral fibula transposition for the augmentation of the reconstruction. Two surgical revisions 28 days after the first surgery were caused by wound necrosis. We achieved complete wound healing by meshed skin transplantation. The bone osteotomy healing was successful 11 months postoperatively.

\section{Patient 2}

32-year-old patient with Ewing sarcoma of the scapula. After subtotal resection leaving a small part with the glenoid fossa, the autograft was replanted and fixed by plate osteosynthesis. Revision on the fifth postoperative day was necessary because of hematoma. The osteotomy developed a stable pseudarthrosis, the function of the shoulder is satisfactory after 11 years of follow-up.

\section{Patient 3}

29-year-old patient with Ewing sarcoma of calcaneus. After total resection and irradiation of the bone, augmentation with bone cement and replantation was performed. Full weight bearing and free walking was achieved 15 months after surgery. This patient died 2.5 years after surgery due to pulmonary metastases.

\section{Patient 4}

36-year-old patient with Ewing sarcoma of calcaneus. After partial resection of the dorsal part of calcaneus and irradiation, the graft was augmented with bone cement and osteosynthesis was performed (screws). Two revisions were necessary because of wound healing impairments within the first 4 weeks. After wound healing, the patient was able to walk free without local pain and is alive 6.5 years after surgery.

\section{Discussion}

The reconstruction of bone defects is not a trivial task and several strategies are available: endoprostheses, allografts, autologous fibula grafts, allogeneic bone grafts, bone segment transfer and sterilized autologous grafts.

The option of reconstruction by means of megaprostheses allows for the rapid stabilization of the affected bone or joint. Full weight bearing and predictable good function of the extremity can be achieved rapidly after bony integration of the stems within 4-8 weeks. However, there are only few reports on long-term results with these megaprostheses, but for intercalary reconstruction, they have a loosening rate of $25 \%$ within a rather short follow-up time of 14 months. The most critical location appears to be the femur [9]. In endoprosthetic joint replacements, Grimer et al. presented their results with a mean follow-up of 29 years. Every patient required on average 2.7 further operations during the follow-up period with the risk of infection being $1 \%$ per year of life and every further operation increasing the infection risk by $2.7 \%$. The risk of secondary amputation was $16 \%$ [10]. Our revision rate (2.54 per case) is comparable with that reported for endoprosthetic reconstruction. Because of the long-term results observed by Grimer et al. and an increasing risk of complications over time, the option of biological reconstruction becomes more important especially for young patients. 
The long-term observation of patients after biological reconstruction by irradiated autografts confirms this thesis [11].

One of the latest published studies presents the results of 64 patients with allograft reconstruction of a resection defect in the lower extremity. The overall survival of the reconstructions was $90 \%$ after 15 years. $6 \%$ of patients underwent secondary amputation of the limb. At least one surgical revision was needed in $40.6 \%$ of patients [12]. Especially the diaphyseal reconstructions seemed to be difficult: $70 \%$ of these patients needed an operative revision and in $40 \%$ of them, non-union was the reason for the reoperation [13].

The rate of revision surgeries in our series was 59\%. Pseudarthrosis was the primary reason for revision in $27 \%$ of patients ( $46 \%$ of all reoperations). Despite this, the osteotomy healing time was comparable between diaphyseal and other locations. The diaphyseal location appears to have a higher failure rate of the mechanical reconstruction in the early phase of healing because of the high mechanical load on a small bone diameter. One possible explanation is the differences in bone biology and in mechanical behavior between these bone parts [14].

Because of the most common complication being pseudarthrosis, we analyzed the factors that could have influenced the outcome. In our patient cohort, we were unable to identify any predictive factors for a successful osteointegration. The length of the reimplanted bone segment within the group with failed reconstructions was longer, but at the same time, this is a factor, which is determined by the tumor extent. The literature contains more work on the role of fibular autograft interposition with or without vascular supply. The role of vascular supply is not yet finally clarified. Manfrini at al could not show a positive influence of pedicled fibula autograft on the surgical revision rate (incl. pseudarthrosis) [15]. Other publications showed an advantage of the vascularized fibula in the case of an irradiated tumor bed or of perioperative chemotherapy [16]. The extensive review by Allsopp et al. in 2016 found no advantages with vascular reconnection of fibular grafts. On the other hand, their work provides evidence of an even higher complication rate with vascularized autografts [17].

The type of sterilization of the bone graft also appears to have an influence on the healing capacity of the so treated bone. One experimental series demonstrated the lowest rate of pseudarthrosis after the replantation of irradiated bone in comparison to pasteurized or autoclaved bone [18]. We used the technique of autograft sterilization by irradiation. The radiation dose necessary to guarantee necrosis of tumor tissue with extracorporal irradiation was calculated to be $250 \mathrm{~Gy}$ [19]. In the published literature, an application of radiation dosages between 50 to 300 Gy are described. We used 300 Gy to be on the safe side with respect to tumor necrosis. The negative effects of irradiation on bone biology are well established [20-22]. We did not observe any cases of autograft fracture in our cohort. For irradiated grafts and using a low dose of irradiation, the cadaver study by Hernandez et al. did not show any influence on the biomechanical properties of the irradiated bone [23]. These findings might explain to a large extent the reconstruction failures and minimally longer time of osteotomy healing in our cohort, compared to other studies $[24,25]$. Further studies would be required to further evaluate the influence of the irradiation dose on the clinical result after the bone reconstruction by irradiated autograft.

\section{Conclusion}

One established method to reconstruct bone defects after tumor resection is the replantation of the irradiated autograft. The rate of complications with this method in our hands is comparable to previously published studies and to alternative methods of bone reconstruction (e.g. prostheses). In our opinion, this method is best suited for young patients with extraarticular bone tumors. However, these patients should be ready to accept longer treatment periods.

\section{Abbreviations}

MRI: magnetic resonance imaging; CT: computed tomography; PET-CT: positron emission tomography-computed tomography; Gy: gray; cm: centimeter

\section{Acknowledgements}

Not applicable.

\section{Authors' contributions}

AK, FR and HRD designed the study. AK, YB and ABM performed the formal analysis and data investigation. AK wrote the original draft. FR, CB; ABM and HRD reviewed and edited the article. All authors read and approved the final manuscript. Every Author agreed both to be personally accountable for the author's own contributions and to ensure that questions related to the accuracy or integrity of any part of the work.

\section{Funding}

-The authors did not receive support from any organization for the submitted work.

- No funding was received to assist with the preparation of this manuscript. - No funding was received for conducting this study.

- No funds, grants, or other support was received. Open Access funding enabled and organized by Projekt DEAL.

Availability of data and materials

The datasets used and/or analysed during the current study are available from the corresponding author on reasonable request.

\section{Declarations}

Ethics approval and consent to participate

This study was performed in line with the principles of the Declaration of Helsinki. Approval was granted by the local Ethics Committee of LudwigMaximilians-University Munich (07.02.2018, reference number 17-891).

Consent for publication

Not applicable.

Competing interests

The authors declare that they have no competing interests. 


\section{Author details}

Musculoskeletal Oncology, Department of Orthopaedics, Physical Medicine and Rehabilitation, University Hospital, Marchioninistr. 15, 81377 Munich, Germany. ${ }^{2}$ Department of Orthopaedics, Physical Medicine and Rehabilitation, University Hospital, LMU, Munich, Germany. ${ }^{3}$ Department of Radiotherapy and Radiation Oncology, Landeskrankenhaus, Paracelsus Medical University, Salzburg, Austria. ${ }^{4}$ Department of Radiology, University Hospital, LMU, Munich, Germany.

Received: 4 January 2021 Accepted: 18 August 2021

Published online: 31 August 2021

\section{References}

1. Picci P, Manfrini M, Fabbri N, Gambarotti M, Vanel D: Atlas of musculoskeletal tumors and tumorlike lesions. : Springer, Switzerland; 2014.

2. Panagopoulos GN, Mavrogenis AF, Mauffrey C, Lesensky J, Angelini A, Megaloikonomos PD, et al. Intercalary reconstructions after bone tumor resections: a review of treatments. Eur J Orthopaedic Surg Traumatol. 2017; 27(6):737-46. https://doi.org/10.1007/s00590-017-1985-x.

3. Spira $E$, Lubin E. Extracorporeal irradiation of bone tumors. A preliminary report. Isr J Med Sci. 1968;4(5):1015-9.

4. Gur E, Kollender Y, Meller I, Amir A, Zaretski A, Bickels J: The use of free vascularized fibular grafts for reconstruction of segmental bone defects. In: Operative techniques in orthopaedic surgical oncology. edn. Edited by Malawer M: Lippincott Williams \& Wilkins, Philadelphia; 2012.

5. Le Deley MC, Paulussen M, Lewis I, Brennan B, Ranft A, Whelan J, et al. Cyclophosphamide compared with ifosfamide in consolidation treatment of standard-risk Ewing sarcoma: results of the randomized noninferiority EuroEWING99-R1 trial. J Clin Oncol. 2014;32(23):2440-8. https://doi.org/10.1200/ JCO.2013.54.4833.

6. Ferrari S, Bielack SS, Smeland S, Longhi A, Egerer G, Sundby Hall K, et al. EURO-B.O.S.S.: a European study on chemotherapy in bone-sarcoma patients aged over 40: outcome in primary high-grade osteosarcoma. Tumori. 2018;104(1):30-6. https://doi.org/10.5301/tj.5000696.

7. Marina N, Bielack S, Whelan J, Smeland S, Krailo M, Sydes MR, et al. International collaboration is feasible in trials for rare conditions: the EURAMOS experience. Cancer Treat Res. 2009;152:339-53. https://doi.org/1 0.1007/978-1-4419-0284-9_18.

8. Krieg AH, Hefti F. Reconstruction with non-vascularised fibular grafts after resection of bone tumours. J Bone Joint Surg Brit Vol. 2007;89(2):215-21.

9. Benevenia J, Kirchner R, Patterson F, Beebe K, Wirtz DC, Rivero S, et al, Outcomes of a modular intercalary Endoprosthesis as treatment for segmental defects of the femur, tibia, and Humerus. Clin Orthop Relat Res. 2016:474(2):539-48. https://doi.org/10.1007/s11999-015-4588-z.

10. Grimer RJ, Aydin BK, Wafa H, Carter SR, Jeys L, Abudu A, Parry M: Very longterm outcomes after endoprosthetic replacement for malignant tumours of bone. Bone Joint J 2016, 98-b (6):857-864.

11. Outani H, Takenaka S, Hamada K, Imura Y, Kakunaga S, Tamiya H, et al. A long-term follow-up study of extracorporeal irradiated autografts in limb salvage surgery for malignant bone and soft tissue tumors: a minimum follow-up of 10 years after surgery. J Surg Oncol. 2020;121(8):1276-82. https://doi.org/10.1002/jso.25918.

12. Muratori F, Totti F, D'Arienzo A, Scorianz M, Scoccianti G, Beltrami G, et al. Biological intercalary reconstruction with bone grafts after joint-sparing resection of the lower limb: is this an effective and durable solution for joint preservation? Surg Technol International. 2018;32:346-5.

13. Bus MP, Dijkstra PD, van de Sande MA, Taminiau AH, Schreuder HW, Jutte $P C$, et al. Intercalary allograft reconstructions following resection of primary bone tumors: a nationwide multicenter study. J Bone Joint Surg Am. 2014; 96(4):e26. https://doi.org/10.2106/JBJS.M.00655.

14. Blokhuis TJ. Management of traumatic bone defects: metaphyseal versus diaphyseal defects. Injury. 2017;48(Suppl 1):S91-s93. https://doi.org/10.1016/ j.injury.2017.04.021.

15. Manfrini M, Bindiganavile S, Say F, Colangeli M, Campanacci L, Depaolis M, et al. Is there benefit to free over Pedicled vascularized grafts in augmenting Tibial intercalary allograft constructs? Clin Orthop Relat Res. 2017;475(5):1322-37. https://doi.org/10.1007/s11999-016-5196-2.

16. Malizos KN, Nunley JA, Goldner RD, Urbaniak JR, Harrelson JM. Free vascularized fibula in traumatic long bone defects and in limb salvaging following tumor resection: comparative study. Microsurgery. 1993;14(6):36874. https://doi.org/10.1002/micr.1920140603.
17. Allsopp BJ, Hunter-Smith DJ, Rozen WM. Vascularized versus nonvascularized bone grafts: what is the evidence? Clin Orthop Relat Res. 2016;474(5):1319-27. https://doi.org/10.1007/s11999-016-4769-4.

18. Yasin NF, Ajit Singh V, Saad M, Omar E. Which is the best method of sterilization for recycled bone autograft in limb salvage surgery: a radiological, biomechanical and histopathological study in rabbit. BMC Cancer. 2015;15(1):289. https://doi.org/10.1186/s12885-015-1234-9.

19. Weichselbaum RR, Rotmensch J, Ahmed-Swan S, Beckett MA. Radiobiological characterization of 53 human tumor cell lines. Int J Radiat Biol. 1989;56(5):553-60. https://doi.org/10.1080/09553008914551731.

20. Nguyen H, Morgan DA, Forwood MR. Sterilization of allograft bone: effects of gamma irradiation on allograft biology and biomechanics. Cell Tissue Bank. 2007;8(2):93-105. https://doi.org/10.1007/s10561-006-9020-1.

21. Sabo D, Brocai DR, Eble M, Wannenmacher M, Ewerbeck V. Influence of extracorporeal irradiation on the reintegration of autologous grafts of bone and joint. Study in a canine model. J Bone Joint Surg Brit Vol. 2000;82(2): 276-82. https://doi.org/10.1302/0301-620X.82B2.9447.

22. Rahman N, Khan R, Badshah S. Effect of $x$-rays and gamma radiations on the bone mechanical properties: literature review. Cell Tissue Bank. 2018;19(4): 457-72. https://doi.org/10.1007/s10561-018-9736-8.

23. Hernandez CJ, Ramsey DS, Dux SJ, Chu EH, Rimnac CM. Irradiation does not modify mechanical properties of cancellous bone under compression. Clin Orthop Relat Res. 2012;470(9):2488-95. https://doi.org/10.1007/s11999011-2148-8.

24. Friedrich JB, Moran SL, Bishop AT, Wood CM, Shin AY. Free vascularized fibular graft salvage of complications of long-bone allograft after tumor reconstruction. J Bone Joint Surg Am. 2008;90(1):93-100. https://doi.org/1 $0.2106 / J B J S . G .00551$

25. Li J, Wang Z, Guo Z, Chen GJ, Fu J, Pei GX. The use of allograft shell with intramedullary vascularized fibula graft for intercalary reconstruction after diaphyseal resection for lower extremity bony malignancy. J Surg Oncol. 2010;102(5):368-74. https://doi.org/10.1002/jso.21620.

\section{Publisher's Note}

Springer Nature remains neutral with regard to jurisdictional claims in published maps and institutional affiliations.

Ready to submit your research? Choose BMC and benefit from:

- fast, convenient online submission

- thorough peer review by experienced researchers in your field

- rapid publication on acceptance

- support for research data, including large and complex data types

- gold Open Access which fosters wider collaboration and increased citations

- maximum visibility for your research: over $100 \mathrm{M}$ website views per year

At BMC, research is always in progress.

Learn more biomedcentral.com/submission 